\title{
WHERE DO WE GO FROM HERE?
}

The problem of substance abuse and dependence has gained much attention in recent years among the general public and the medical profession in this century. Both governmental and non-governmental agencies are involved in the attempt to combat this ever increasing problem and crores of rupees have boen spent on it. However, when one surveys the national scene, one is struck by the lacunae in our knowledge and the inadequacies of our intervention programs.

Both pharmacological and psychosocial methods of treatment are available for the treatment of substance use disorders. Success of these methods however, even when used in combination is at best modest. The conflict among agencies which tend to look up on substance use either as a purely medical problem or as a purely psychosocial problem has resulted in a restricled and narrow approach to treatment, thus depriving the patient of even the litte benefit he would bave got by having an integrated approach which makes use of all the available methods of treatment.

Often one comes across medical men actively involved in the care of persons with substance abuse and dependence, whose concept of treatment consists only of admitting the patient to a hospital, detoxifying him and then sending him home with the advice to refrain from further use of the substance or at the most giving a didactic talk on the adverse effects of the substance use. Similarly some voluntary agencies trying to help substanoe dependent persons either are averse to the use of pharmacological measures or do not have access to professional belp to make use of such methods. What is required is a concerted effort using all the methods of intervention available to prevent the person from relapsing into his old habit.

Evaluation of the various methods of treatment individually or in combination is an arca which needs attention. Evaluation studies so far have been confined to the treatment of alcohol dependence and there are hardly any studies which examine the effects of treatment in other substance abuse problems. Out of the twenty one articles on substance abuse / dependence published in the Indian Journal of Psychiatry during the last five years, only two have dealt with treatment of non-alcohol substance use.
While we have had a fair number of epidemiological studies on the prevalence of substance dependence or abuse in various vulnersble segments of population like Zulfikar and Vankar's study on medical students reported in this issue, it is time that we concentrate on the specific aspects of the problem, which have a bearing on intervention and outcome. Kishore et al in this issue report a life time prevalence of co-morbidity in $60 \%$ of those with alcohol dependence and opioid dependence. While comorbid conditions may have an etiological role in some patients with substance dependence, in many it may lead to a poor treatment outcome, untess the comorbid condition is also recognized and effectively deall with. This finding is an extremely important one which should wam us against the tendency to see substance abuse / dependence as a problem which needs only social or legislative intervention. It also underlines the important role psychiatrists bave in the management of these problems.

Future epidemiological studies also should pay attention to the prevalence of combined use of alcohol and other drugs among substance users. Western studies have reported this to vary from $29 \%$ to $95 \%$ (Ghodse, 1994). Availability of such data is important because combined use of alcohol and other drugs alters the pharmacokinetics of these substances and their behavioral effects which can be additive or even synergis ${ }^{t}$ ic. Follow-up studies have shown that treatment outcome in combined users are poorer and their psychosocial functioning worse than that of single substance users.

Most of the epidemiological studies in this area are dependent exclusively or largely on the selfreport by the patient himself. Coexistence of psychiatric disorder, presence of toxic or withdrawal symptoms, memory lapses resulting in poor recall of past details, poor motivation for treatment, doubts about confidentiality etc., are factors which distort self reports on substance usc. Even the type of questions used in surveys are found to influence the reliability of the information gathered. For example, Sleinweg and Worth (1993) have shown that openended questions on drinking habits elicit more revealing information than direct close-ended ones. These observations point to the need to develop 


\section{K.KURUVLLA}

more objective, reliable and culturally sensitive instruments for epidemiological studies.

Sociocultural factors are of prime importance in the causation, pattern and outcome of substance use disorders. Recent studies have dra wn our attention to the heterogeneity of substance users and the need to study not only similarities in patterns of use but also the differences, so that our preventive and therapeutic efforts can be made appropriate to the specific cultural group we are dealing with. The peper by Wairagkar et al, in this issue of the Joumal, on addiction to codeine containing cough syrup in Assam and Nagaland illustrates this point. It shows how characteristics of substance use vary not only from country to oxuntry or from region to region within the same country, but also between two neighboring states, thus highlighting the need to tailor our intervention strategies to the specific problems seen in each community.

Pyychiatric sequelae of many substances of abuse is another area where our knowledge is very limited. Basu et al show in their review article that in spite of our vast experience with cannabis users we are still uncertain about the existence of chronic cannabis psychosis or amotivational syndrome. As these authors point out, psychiatrists in this country have the unique opportunity to conduct studies which hopefully will shed light on some of these reas of ignorance.

Most workers in the field of substance use disorders would agree that our ability to treat these problems is limiled and so we ought to concentrate on prevention. There is however very little agree- ment on the appropriate methods to prevent drug abuse or dependence. Very tittle data is availabic on the effectiveness of measures which have been so far used, like restricting the availability of aloothol and having health warning labels on cigarette packets. Here again it is important to be aware of the sociocultural factors which influence substance use and adopt culturally sensitive intervention strategies and health education programs rather than believing that there gre universally applicable methods. This is yet another area where inlegration of biomedical and social science approaches are likely to provide us with more useful information than isolated endeavors.

In the evaluation of governmental policies to control alcohol use, India can be considered as a natural laboralory, with policies varying not only from stale to state but even from ministry to ministry in the same state because of political pressures and economic compulsions. Studies aimed al evaluation of these varying policies could be of great use in formulating fulure policies.

K.KURUVILLA

\section{REFERENCES}

Ghodse, H. (1994) Combined use of Drugs and Alcohol. Current Opinion in Psychiary, Vol.7, $249-251$.

Steinweg, D.L \& Worth, H. (1993) Alcoholism: The Keys to the CAGE. American Joumal of Medicine, Vol.94, 520 - 523. 